\title{
The Virginia Fisheries Laboratory
}

\author{
By
}

J. L. McHUGH and ROBERT L. MARBLE

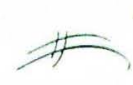

Virginia Fisheries Laboratory

Contribution $\mathrm{No}_{3} 36$ 

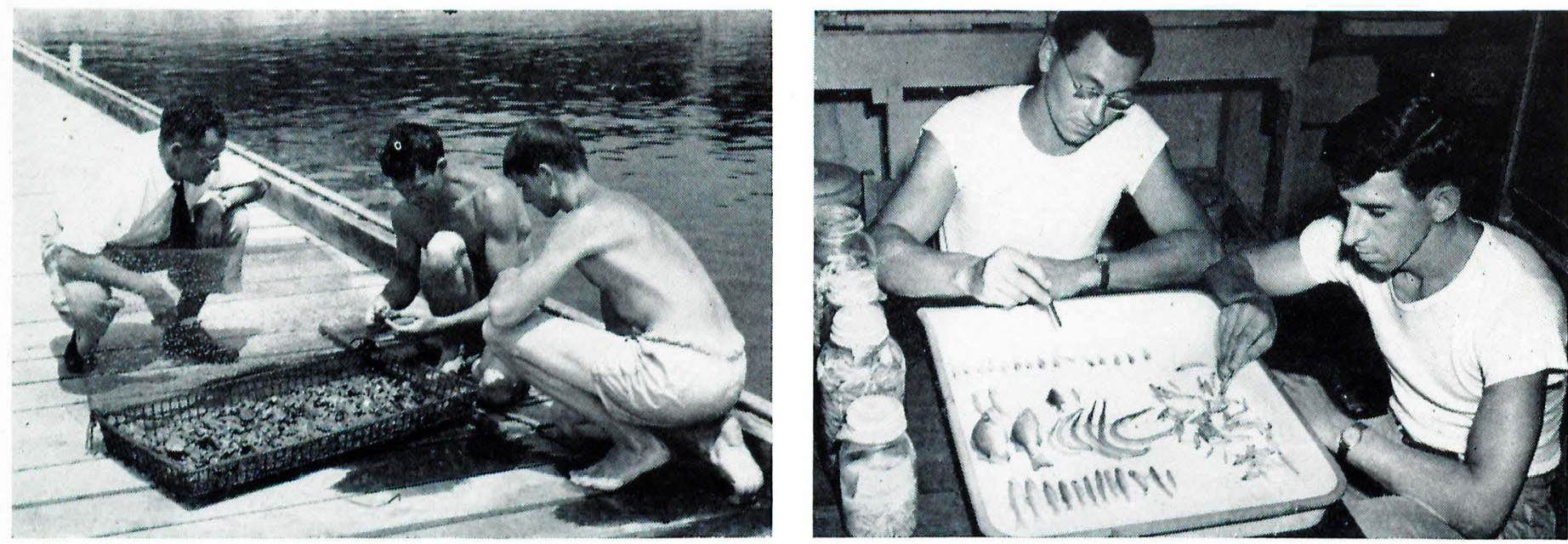

Left: Dr. McHugh, Dr. Jay D. Andrews, and Frank Carey examine a tray of oysters at the pier of the Virginia Fisheries Laboratory. Right: Graduate students H. N. McCutcheon and E. C. Ladd sorting fish collections from the Rappahannock River.

\section{The Virginia Fisheries Laboratory}

STATE-Supported fishery research and enforcement of fishery laws are investments by the people of Virginia in the future of their fishery resources. The purpose of such investment of state funds may be the rehabilitation of declining seafood production, but in the long view it is concerned properly with the assurance of a sustained yield to the fisherman.

The Virginia Fisheries Laboratory, and its parent agency the Commission of Fisheries, have been established by law to carry out these objectives. The Laboratory is required to obtain the basic information on which sound legislation must be based; the commission is empowered to enforce the regulations that are established by statue.

EVENTS LEADING TO THE ESTABLISHMENT of a fisheries laboratory in Vifginia began in 1930, when the General Assembly directed the state health commissioner and the commissioner of fisheries to plan a laboratory and to employ a biologist. In 1931, Dr. Victor L. Loosanoff, now director of the U. S. Fish and Wildlife Service Laboratory at Milford, Connecticut, was hired, and established a laboratory at Newport News. In 1932 this activity was abandoned for lack of assured funds.

In the period 1932 to 1940 , support of biological research was limited to the provision of vessels to be used in blue crab studies by the University of Maryland and the Maryland Conservation Com-

Dr. McHugh is director of the Virginia Fisheries Laboratory at Gloucester Point; Mr. Marble is manager of the Gloucester-Mathews Bureau of the Newport News Daily Press.

By

\section{J. L. McHUGH \\ and}

\section{ROBERT L. MARBLE}

mission. In addition, the U. S. Bureau of Fisheries conducted some studies of screwborers, and established a laboratory at Yorktown to investigate the effects of pulp mill wastes on the oyster industry in the York River.

In 1940, funds were provided by the Virginia legislature to establish the Virginia Fisheries Laboratory. Quartered first at the College of William and Mary, later at Yorktown, and under the direction of Dr. Curtis L. Newcombe, the laboratory

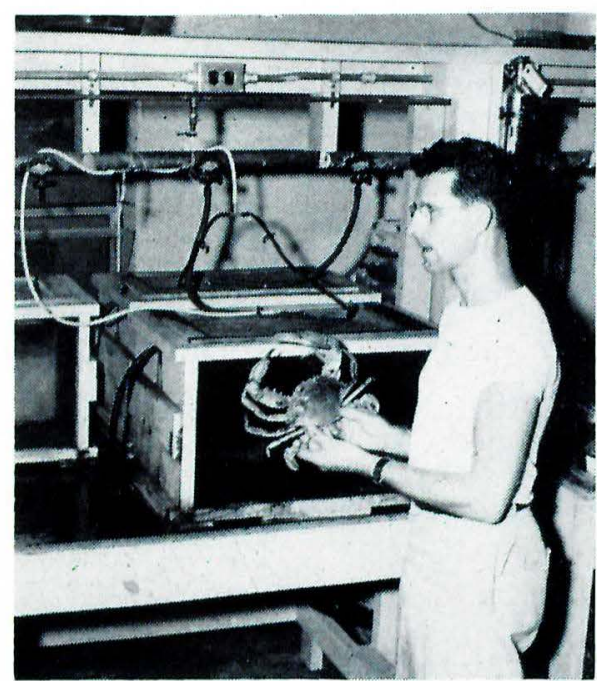

W. A. Van Engel is studying the blue crab fishery as part of the Laboratory's work undertook a biological survey of the tidal waters with special attention to the shellfisheries.

From 1940 to 1946 , investigations were conducted on oysters, blue crabs, mussels, catfish, and other marine forms. In 1946, a complete reorganization of the staff took place, as a result of which two of the present staff members were employed as replacements. These men, Dr. Jay D. Andrews and W. A. Van Engel, concerned themselves with research on oysters and blue crabs, respectively.

In 1947, Dr. Nelson Marshall took over direction of the laboratory. He added to the staff William H. Massmann and Dexter S. Haven to study the shad and croaker fisheries. Also employed were a biologist to direct educational activities, and an administrative assistant.

In 1949, Dr. Marshall accepted a position as dean of the College of William and Mary. Although his new duties placed great demands on his time, he continued as acting director of the laboratory, and in this period supervised a development of considerable significance, the construction of a new building at Gloucester Point, which was completed and occupied late in 1950.

This two-story, brick and cinder block structure, located on the York River near the north approach to the new George P. Coleman Memorial Bridge, provides labratory and office accommodations for a staff of five biologists, administrative and clerical assistants, educational director, and graduate students. Space can be made available readily for classes or visiting groups of as many as fifty persons. 
On the ground floor are the offices of the director, administrative assistant, secretary, and educational director. A large classroom, equipped with running sea water, may be converted into two smaller laboratories or offices by lowering a vertical panel. A small darkroom is available for photographic work. A public exhibit room, containing panels and displays of local marine life, and aquaria holding local fishes and shellfish, serves double duty as a lecture room or theater. A preparation room adjoins the education office and exhibit room, and a mimeograph and mail room contains space for storage of office materials.

The center of the upper floor is occupied by a large laboratory, provided with running sea water for experimental studies. Surrounding this are four small offices for staff biologists, two cubicles for secretaries or graduate students, a chemical laboratory, a chemical stock room including an electrically-operated dumbwaiter for the handling of heavy containers, and a cold room with running sea water for controlled temperature experiments. At one end of the upper floor are two small dormitories for students and visiting scientists, each provided with washroom and shower. A tiny modernlyequipped kitchen, a technical library, and a film reading room are also located on this floor.

Associated facilities include a substantial pier with salt-water pumps, tide gauge recording station, berthing facilities for boats, and fresh-water and electrical connections. Seagoing equipment consists of a fifty-foot research vessel, a smaller motor launch, and several small boats. The wellequipped workshop has cold room and storage space for nets and other gear. Five large outdoor salt-water tanks provide nearly natural conditions for experiments on living animals.

THE laws of VIrginia describl: THE functions of the laboratory as follows:

The Fisheries Laboratory shall conduct studies and investigations covering the seafood industry as a whole, and shall make annual reports of its findings to the Commission of Fisheries; and shall, in addition thereto, make such special studies and investigations touching any part of the seafood industry as it may be requested to do by either the Commission of Fisheries, or the Governor of Virginia.

To perform these broad responsibilities adequately would require a staff many times the size of that now employed. Consequently, emphasis has been concen-

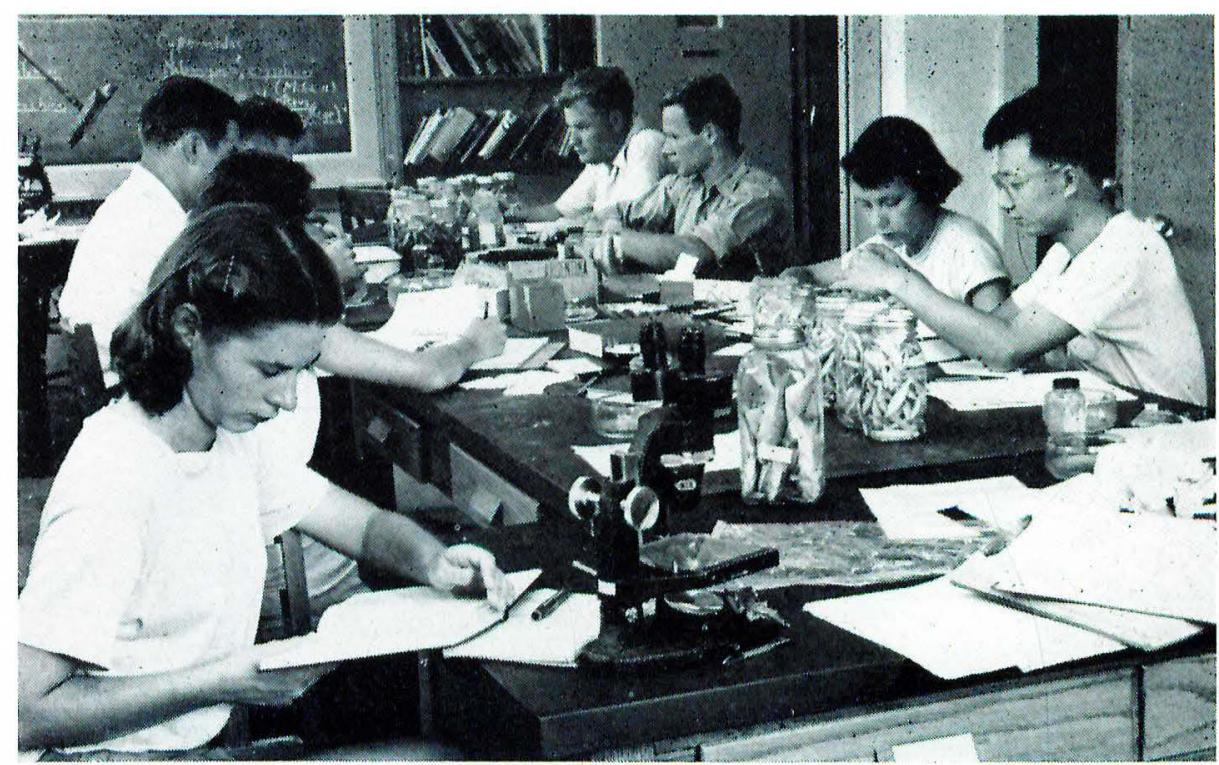

Summer school students at the Laboratory, a division of William and Mary College

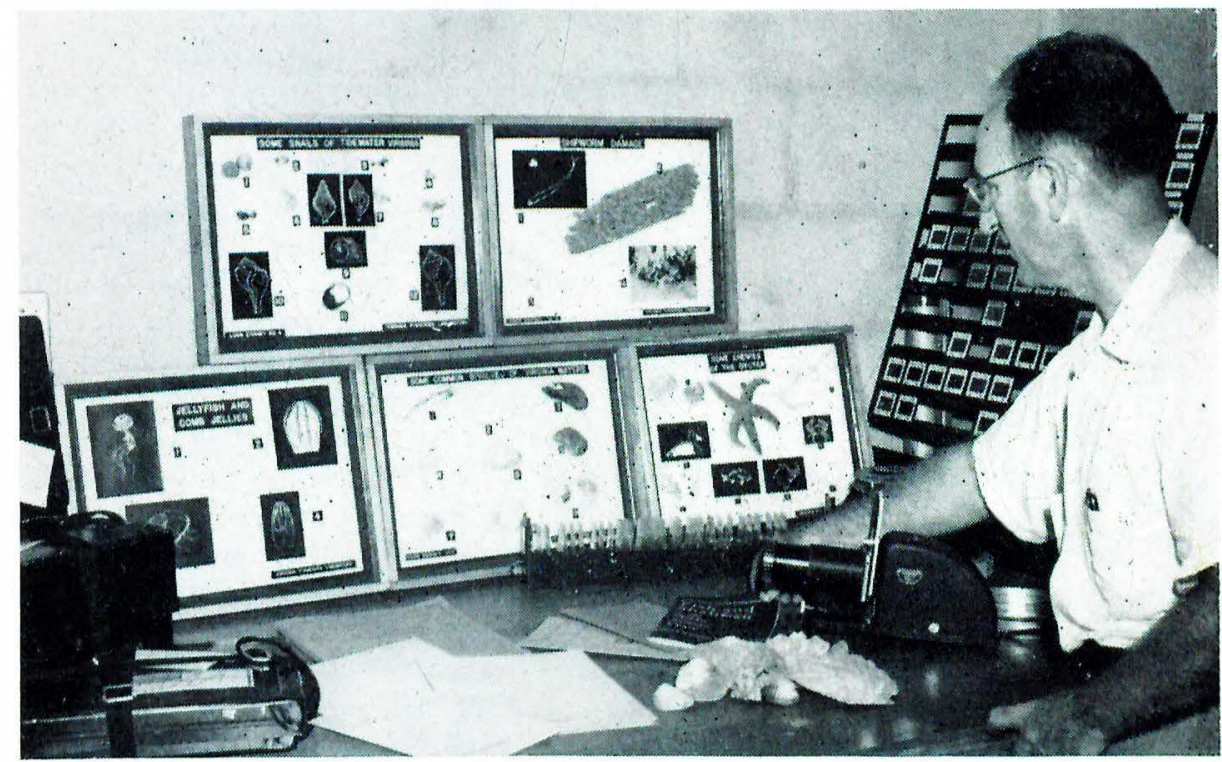

Robert S. Bailey prepares exhibit cases for use in schools of Tidewater Virginia

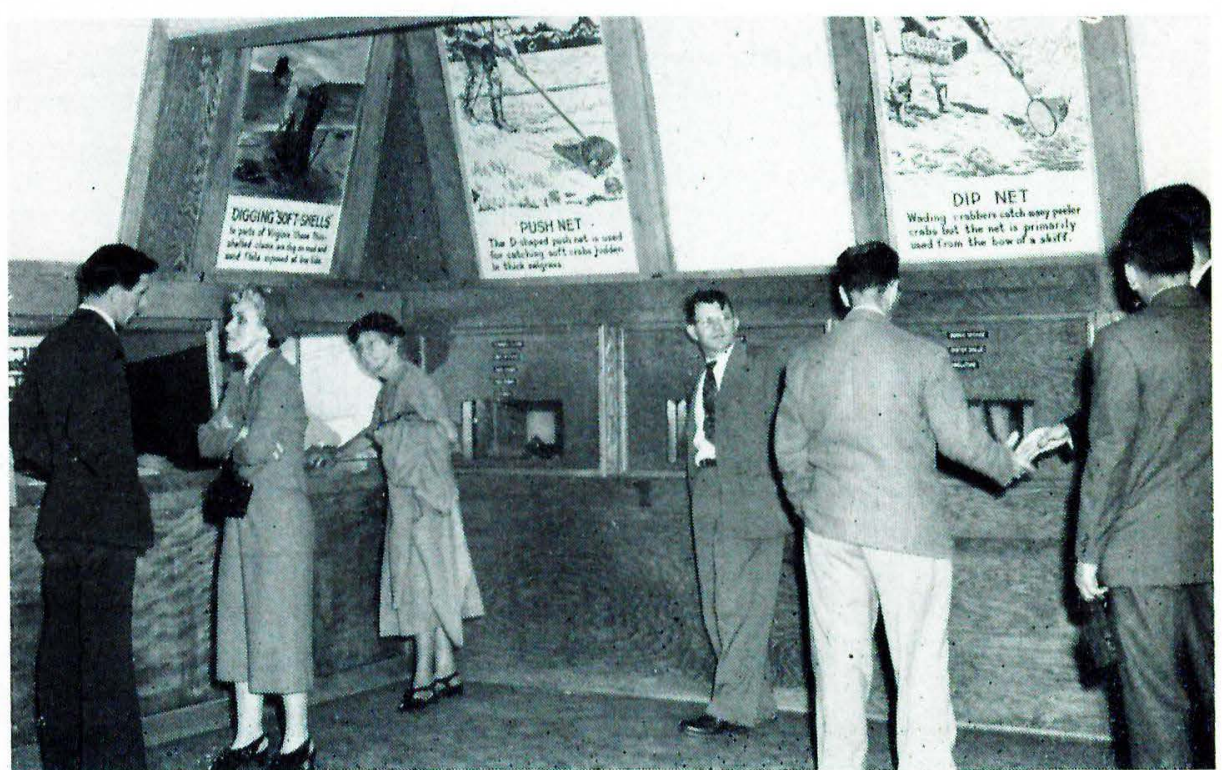

A public exhibit room contains panels and displays of marine life of this region

[3] 

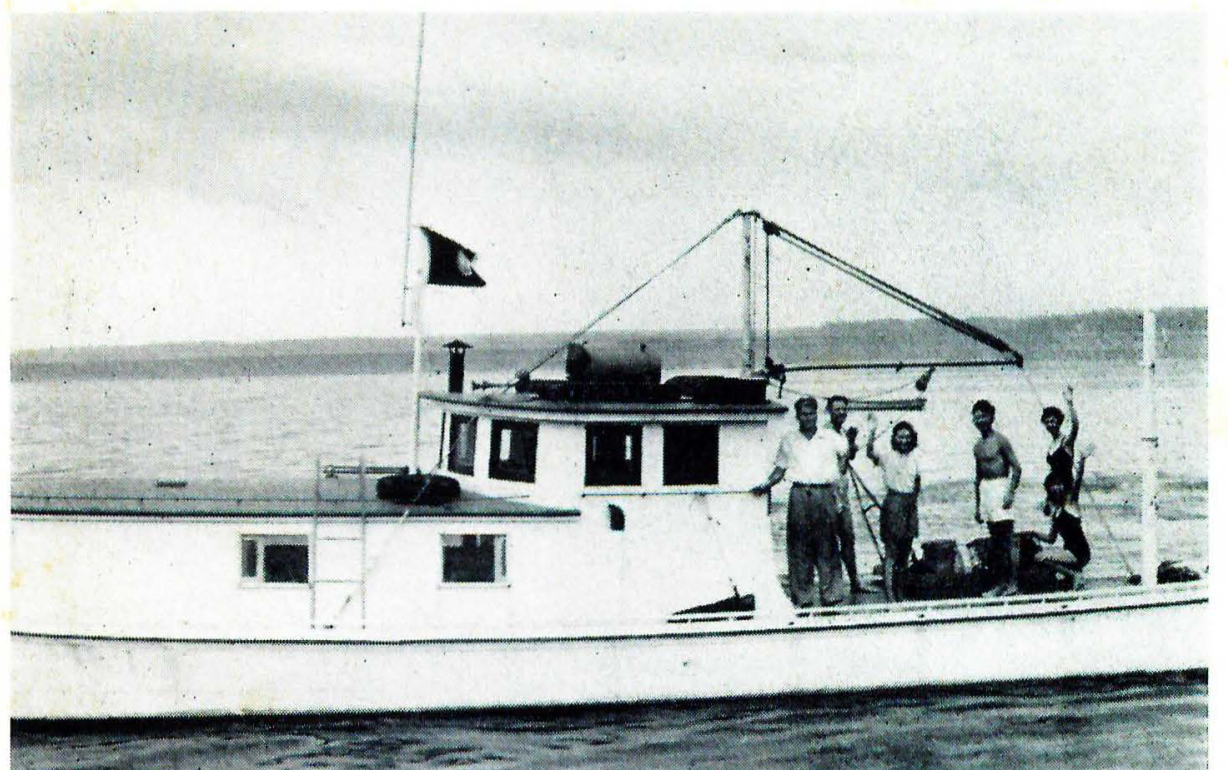

The Laboratory's research vessel Virginia Lee cruises Chesapeake Bay and its estuaries, gathering information on seafoods and training students in marine biology

trated on investigations of four fisheries of major importance, the oyster, the blue crab, the croaker, and the shad. Considerable progress has been made toward an understanding of the habits and lives of these important seafoods, and of the effects of the fisheries and of natural and artificial conditions on their abundance. These findings have already formed the basis of recommendations for improved production, and further recommendations will be advanced as knowledge increases.

Various special projects occupy the attention of the staff from time to time. Industrial and domestic pollution constantly threaten the fisheries, and close cooperation is maintained with the State Water Control Board and the federal Department of Public Health in studies of the effects of waste disposal. Declining catches of certain species are attributed to a number of causes. Thus, the recent alarming drop in croaker catches has been blamed on the destruction of young fish by the North Carolina shrimp trawlers. The Laboratory is participating actively in an investigation of these and other problems.

The Laboratory biologists do not confine their research activities to the York River. Extensive research has been conducted on the oyster grounds of all the Virginia rivers, and studies of shad, rock, and other fishes take research personnel into the Rappahannock, Pamunkey, Mattaponi, and James rivers. Other investigations cover the Chesapeake Bay and the Atlantic Ocean.

The Laboratory is actively participating in cooperative research with other scientific groups along the Atlantic coast. These cooperative efforts provide information practically unobtainable by any one of the groups alone, but vastly important to the conservation of all our seafoods.

Virginia biologists work hand in hand with those of the U. S. Fish and Wildlife Service, the Chesapeake Bay Institute of the Johns Hopkins University, and the Chesapeake Biological Laboratory of the Maryland Department of Research and Education. Through the medium of the Atlantic States Marine Fisheries Commission, the work of these and many other state and federal agencies is coordinated.

IN ITS FUNCTION AS A DIVISION OF THE College of William and Mary, the Laboratory is responsible for the training of graduate students working toward the Master's Degree in Aquatic Biology. In this way it is helping to provide a nucleus of marine and fishery biologists qualified to investigate the specialized problems encountered in bays and estuaries.

PUBLIC SUPPORT OF RECOMMENDATIONS advanced for the general benefit of the seafood industry is imperative. Measures suggested for the benefit of the fishing industry are often regarded with suspicion by the industry and the public. The biologists believe that this distrust is caused by a lack of understanding of the fundamental principles of biology. Two examples may help to show how such misunderstandings come about. The recent decline in croaker landings has had serious effects on the industry. Speculation as to the reasons for the disappearance of the croaker has pointed variously to the North Carolina shrimp fishery, to the winter trawl fishery off the Virginia capes, or to a change in the migration pattern of this important species. The biologist knows of at least two additional possible explanations: removal by excessively heavy fishing of the reserve supply of fish so necessary for economically sound production, and fluctuation in the success of spawning from year to year. To the general public the concept of large-scale variations in spawning success seems to be difficult to grasp, although the phenomenon is almost universal in the ocean. Several years of spawning failure in a fishery that has lost its reserves through heavy fishing, or from any other cause, can only lead to collapse.

Alarm is always expressed when large numbers of young fish are killed by commercial gears or by causes not immediately obvious. The recent complaints occasioned by the capture of young croakers, spot, and other fishes in shrimp trawls have been duplicated in the past in many parts of the world, and considerable effort has been expended in attempts to evaluate the "destructiveness" of such gear. Mass mortalities of young fish, apparently due to some natural cause, at times take place near populated areas, and these give rise to frantic appeals for investigation. Here again fundamental biological principles are ignored, for the rigors of life in the sea are such that countless millions of young fish must die. Nature has allowed for these tremendous mortalities by providing each female with an abundant supply of eggs, and it is not unusual for each fish to spawn several hundreds of thousands of eggs in her lifetime. Destruction of some portion of the young, whether by natural or artificial means, only increases the chances that the remainder will survive and grow. There never has been any clear evidence that protection of young marine fish has materially improved the commercial catch.

Educational activities in the elementary and high schools are an important laboratory function. Public support of scientific management policies requires a general understanding of the principles outlined above. The schools seem to offer the best medium for teaching these principles.

TO BE SOUND, AN INVESTMENT MUST produce reasonable dividends. A statesupported agency has no claim to be exempt from this rule. Successful application of the generally-accepted principles on which good fishery management is based should produce for Virginia dividends in the form of a well-balanced and prosperous fishing industry. 